240

$\mathrm{N} 64-20683$
CAT. CQ COTE-I

OPERATIONAL EXPERIENCE WITH X-15 REACTION CONTROLS

By Calvin R. Jarvis and Elmor J. Adkins

NASA Flight Research Center

Edwards, Calif.

\author{
SAE-ASME Symposium on \\ Position, Attitude and Thrust Vector Control \\ Apriz 27-30, 1964. \\ New York City, N. Y.
}

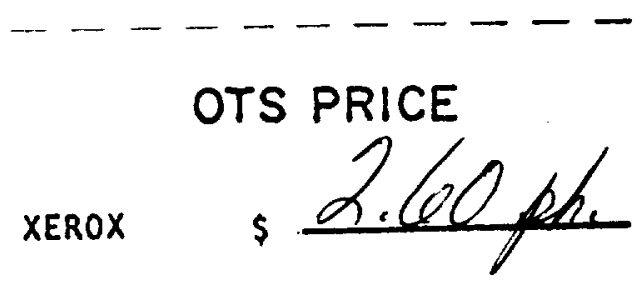

April 21, 1964 
. 
OPERATIONAL EXPERIENCE WITH X-15 REACTION CONTROLS

By Calvin R. Jarvis and Elmor J. Adkins

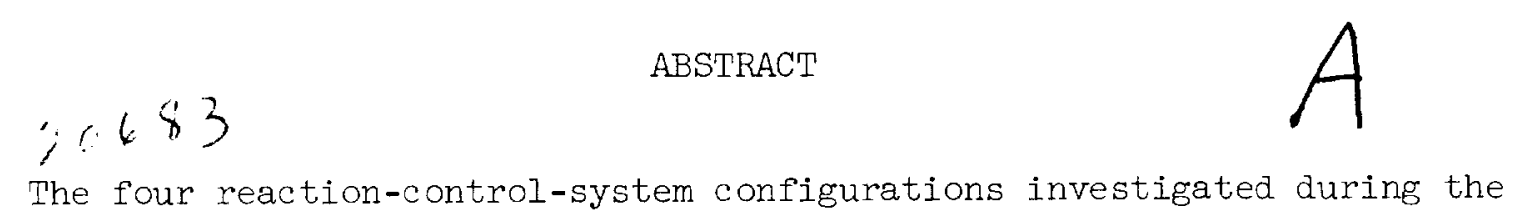

$\mathrm{X}-15$ program include a proportional acceleration command system, on-off

proportional rate command and attitude hold systems, and a rate-sensing on-off

stability augmentation system. Each of the systems is described briefly, and

development problems encountered in hardware design, component compatibility,

and systems integration are discussed. The practical aspects of system design

and operation are emphasized.

Flight experience with each system is also discussed. Flight data showing the results of open-loop and closed-10op control during critical $X-15$ reentry maneuvers are presented.

Acethen 


\title{
OPERATIONAL EXPERIENCE WITH X-15 REACTION CONTROLS
}

\author{
By Calvin R. Jarvis and Elmor J. Adkins \\ NASA Flight Research Center \\ Edwards, Calif.
}

\section{INTRODUCTION}

Interest in the stability and control of manned aircraft in regions of extremely low dynamic pressures was a direct outgrowth of the NACA-NASA research-airplane program. The expansion of flight envelopes with these highperformance vehicles made it necessary to investigate methods of providing adequate control in areas where aerodynamic controls are ineffective. To gain some insight into this problem and, if possible, to anticipate problems that might be encountered in this flight environment, motion and fixed-base simulator studies of several reaction-control-system configurations (ref. 1) were conducted at the NASA Flight Research Center. Flight-test programs were also undertaken with the $X-1 B$ experimental aircraft (ref. 2) and a specially modified F-104A research airplane (ref. 3). These programs helped establish control techniques, effectiveness criteria, and propellant requirements of reaction jet systems for stabilizing and controlling high-altitude reentry vehicles such as the $X-15$, the first airplane designed specifically to investigate control problems at low or zero dynamic pressure.

The first operational reaction control system designed for the $X-15$ was an open-loop acceleration command system. From this basic system evolved three other reaction control systems: a rate-feedback stability augmentation system and closed-loop rate command and att1tude hold systems. These systems were obtained by incorporating various feedback slgnals to generate closed-loop control. $\mathrm{H}-345$ 
This paper discusses problems of hardware design encountered in the development of operational reaction control systems and presents flight data obtained with the various types of control.

\section{DESCRIPTION AND OPERATION OF X-15 REACTION CONTROL SYSTEMS}

The $\mathrm{X}-15$ reaction control systems use hydrogen-peroxide reaction rockets to develop the required control moments about each axis. Locations of the rockets are shown in figure 1 . The rockets for pitch and yaw control each have a maximum thrust capability of 113 pounds, and the rockets used for roll control have a maximum thrust capability of 40 pounds.

A schematic diagram of the basic hardware components of the $\mathrm{X}-15$ reaction control systems is presented in figure 2. Included are a spherical storage tank containing helium for pressurization, an ellipsoidal pressure tank for hydrogenperoxide storage, metering valves for controlling propellant flow to the reaction rockets, and a three-axis control stick. Propellant components not shown in the figure include a propellant shutoff and jettison valve operated by the pilot, a propellant relief valve to prevent overpressurization, and a blowout plug which ruptures if the pressure-relief valve malfunctions.

The hydrogen-peroxide propellant is contained in an expulsion bladder within the ellipsoidal pressure tank. When the pressurized helium is emitted between the expulsion bladder and the tank wall, pressure is exerted on the collapsible bladder forcing the peroxide out of the tank through a perforated metal standpipe and propellant pickup tube.

Control inputs are made by the pilot through the three-axis controller. The controller is mechanically connected to the metering valves which control the flow of propellant to the reaction rockets proportional to control-stick position. 
Each reaction rocket contains a silver-screen catalyst bed to decompose the hydrogen-peroxide propellant and produce oxygen and steam at high pressures and temperatures. The steam is then exhausted through a convergent-divergent nozzle to generate the required thrust.

The same types of basic hardware components were used in the four reactioncontrol-system configurations investigated. Block diagrams of the four configurations are presented in figure 3. For simplicity, only one control axis is represented; the other two axes are identical. The open-loop acceleration command system (fig. 3(a)), designed and built by North American Aviation, Inc., consists of two independent, parallel propellant and rocket systems which are operated by the three-axis controller. The two systems may be operated either separately or simultaneously. Both normally operate simultaneously, with two rockets firing to produce the commanded thrust about each axis. The pitch and yaw rockets for each system are located adjacent to each other in the nose of the vehicle. The roll rockets for each system are arranged in the wing to provide coupled torques about the roll axis. Each system is capable of providing a maximum design angular acceleration of $2.5 \mathrm{deg} / \mathrm{sec}^{2}$ about the pitch and yaw axes and $5 \mathrm{deg} / \mathrm{sec}^{2}$ about the roll axis.

The $X-15$ reaction augmentation system (fig. $3(b)$ ) was manufactured by Nortronics, a Division of the Northrop Corp., and utilizes only one of the two parallel arrangements of the basic acceleration command system. This limits the reaction augmentation system (RAS) control authority to one-half that available to the pilot who has command over both systems. The RAS employs rato gyros which sense the rotational rates of the aircraft about each body axis. The gyro converts the aircraft angular rate to a proportional electrical signal which is amplified in the electronics section. The signal is then used to operate an on-off solenoid control valve which controls the flow of propellant to the rocket motors. Switches are incorporated in the system to prevent 
opposing inputs between the pilot and the reaction augmentation system. These switches are connected directly to the pilot's reaction control stick and disconnect the RAS feedback signal when the controller is displaced from the neutral position. Rate dead-band levels, in which the RAS will be inoperative, are also included and are pre-set during the ground checkout before flight.

The $\mathrm{X}-15$ rate command reaction control system (fig. $3(\mathrm{c})$ ) was designed and manufactured by the Minneapolis-Honeywell Regulator Co. in conjunction with an adaptive-type aerodynamic control system. The same stick and rudder pedals used to provide pitch, roll, and yaw aerodynamic inputs are used by the pilot to provide reaction-control inputs. Thus, it is not necessary for the pilot to transfer from one control stick to another when transition between aerodynamic and reaction controls takes place. Rate gyros are used as feedback-sensing elements in the conventional manner about all three control axes. The gyro outputs are amplified and used to operate on-off solenoid valves which control the flow of propellant to the attitude rockets. The rate command system, like the RAS, utilizes only one of the two parallel propellant and rocket arrangements of the basic acceleration command system. Fixed dead bands in pitch, roll, and yaw are also used to prevent undesirable limit-cycle operation and excessive fuel consumption.

The $\mathrm{X}-15$ attitude-hold reaction control system (fig. $3(\mathrm{~d})$ ) is obtained in the conventional manner by incorporating an attitude feedback loop around the rate command system. Attitude signals for the additional feedback loop are obtained from an inertial platform. The system was designed to hold a reference attitude, selected by the pilot, to within $2^{\circ}$ during zero dynamic pressure. The system can also be operated as an attitude command system about the roll axis. In the pitch channel, the pilot may select either pitch-attitudeangle or angle-of-attack hold. When angle-of-attack feedback is chosen, the system functions to maintain the vehicle angle of attack constant to within $2^{\circ}$. 
Fixor dead bands in pitch, roll, and yaw are also incorporated into the attitude command system.

DEVELOPMENT OF THE X-15 REACTION CONTROL SYSTEMS

\section{Hardware Material}

Although many design and operational problems were encountered during the development of the $\mathrm{X}-15$ reaction control systems, most of the problems concerned the hydrogen-peroxide propellant system. During the early development stages, the reliability of the expulsion system, valves, catalyst beds, and even the selection and fabrication of material presented problems.

Because of the corrosive nature of the 90-percent concentrated hydrogen peroxide, it was difficult to find materials that were compatible with the propellant. Selection of a suitable material for the expulsion bladder was especially difficult, inasmuch as it had to be compatible with the hydrogenperoxide propellant under long-time exposures at low temperatures and had to withstand repeated flexing without fatigue in order not to mupture under highload conditions. The first expulsion bladders were constructed of Teflon, but more recent bladders have been made of Vicone, a fluoro-silicone rubber. Both bladders have functioned satisfactorily except for a tendency to rupture along the creases which are formed after the propellant is fully expelled and the bladder is compressed around the standpipe. This structural deficiency has resulted in a short and inconsistent bladder life.

Proper material for hardware components such as check valves, metering valves, and flow lines was also difficult to select. The original $\mathrm{X}-15$ reaction control system was constructed entirely of aluminum. It was discovered, however, that chemical reaction between the aluminum and the hydrogen-peroxide propellant formed hydroxides. Deposits of these substances resulted in "sticky" valves, short catalyst-bed life, and other component failures. Certain components 
which came into direct contact with the peroxide propellant were then constructed of stainless steel; however, use of the two different metals caused electrolytic action wherever the metals were joined and came into contact with hydrogen peroxide and, thus, resulted in various component failures and contaminated propellant. The entire system was finally constructed of stainless steel which eliminated the problems and increased component reliability.

\section{Heat}

Heat generated by the rocket motors during the decomposition process proved to be a source of trouble. Because of differential thermal expansion, the heat resulted in hydrogen-peroxide leakage between the mating surfaces of the injector and rocket-motor casing. A temporary solution was obtained by welding the injector to the motor casing. This modification eliminated the leakage problem but made it impossible to periodically inspect the catalyst-bed assemblies. The rocket-motor casing was later modified, and a special allmetal seal was designed to provide a leak-tight fit between the injector and motor casing.

Local heat generated by the rocket motors also caused extensive valve-seat damage and loss of spring temper in the injector check valves which were originally located adjacent to the motor assemblies to prevent starting delays during intermittent operation. It was found that satisfactory operation could be obtained by relocating the valves upstream approximately 20 inches.

\section{Pressure Surges}

During early qualification tests of the system, it was discovered that transient pressure surges, resulting from rapid valve operations, were large enough to unseat or open emergency pressure-relief devices and blowout plugs, thus causing complete loss of the rocket propellant. The pressure-relief devices were subsequently modified to allow for the pressure surges. Slower- 
operating valves were also used in some instances to reauce pressure surges.

\section{Environmental Conditions}

The environmental temperature conditions under which the reaction control system was required to function also necessitated special design considerations. Because of the proximity of the propellant flow lines and the X-15 Iiquidoxygen storage tank, it was necessary to heat the lines to prevent the propellant from freezing. Wraparound-type heaters were used on all peroxide ilow lines that were not insulated from ambient-air temperatures. The reactioncontrol metering valves were also heated to maintain a temperature between $59^{\circ} \mathrm{F}$ to $79^{\circ} \mathrm{F}$ that is necessary for normal operation.

Another environmental-temperature problem was wet rocket starting which occurred when the reaction motors were exposed to low ambient temperatures at high altitudes. The reduced motor temperatures resulted in combustion delays and the ejection of raw propellant through the rockets. Electric heaters were subsequently installed around the decomposition chambers to maintain a constant temperature regardless of ambient conditions and to reduce the possibility of wet starts.

\section{Structural Resonance}

Once the hardware problems with the basic acceleration and propellant supply systems were eliminated, incorporation of the closed-loop control systems was relatively easy. Special solenoid on-off control valves were developed that would be compatible with hydrogen peroxide and would function properly in the extreme environmental conditions.

Only one major problem requiring modification was encountered with the closed-loop control systems. It was found that 13 eps structural vibrations at Low dynamic pressures were of sufficient magnitude to be detected by the rateEyro sensors. Thus, the control rockets fired at the 13 cps structural resonant 
frequency and rendered the system ineffective in providing the desired damping moments. To eliminate this problem, the response of the systems was modified by incorporating appropriate filters in the feedback networks. The filters attenuated the signal levels resulting from the stmuctural resonance and insured that valve actuation would not occur at these frequencies.

\section{FIIGHT EXPERIENCE}

Operational experience with the reaction control systems has been obtained from flights with the three X-15 aircraft. All three of the airplanes were equipped with the basic acceleration command systems, two with the reaction augmentation system, and one with the rate command and attitude hold systems.

A typical X-15 high-altitude flight profile is shown in figure 4. After launch and engine ignition, a constant normal-acceleration pullup is initiated and held until the desired pitch attitude is reached. The pilot then generally flies a constant pitch angle with aerodynamic controls until engine burnout occurs. Transition from aerodynamic to reaction controls is accomplished manually, at the pilot's discretion, when the acceleration command or rate damper systems are utilized. Transfer may be accomplished either manually or automatically when using the rate command or attitude hold systems.

During flight in the low-dynamic-pressure regions, the pilot makes compensatory inputs to maintain aircraft control. After the peak altitude is reached, the aircraft begins its descent and it is necessary to establish and maintain a reentry angle of attack. As the dynamic pressure increases at reentry, the load factor builds up and the pilot maintains a constant $3 \mathrm{~g}$ to $5 \mathrm{~g}$ pullup maneuver until the recovery is completed. The automatic reaction control systems may be either manually or automatically disengaged following reentry. The reaction control system is generally effective down to approximately 120,000 feet or to a dynamic pressure of 100 psf. 
The number of flights made with each type of system and the total flight time accumulated with each system below a dynamic pressure of 25 psf are shown in the following table:

\begin{tabular}{|l|c|c|}
\hline \multicolumn{1}{|c|}{ System } & $\begin{array}{c}\text { Number of } \\
\text { flights }\end{array}$ & $\begin{array}{c}\text { Time below } \\
\mathrm{t}_{\mathrm{q}<25} \text {, sec }\end{array}$ \\
\hline Acceleration command & 3 & 318 \\
Augmentation & 1 & 148 \\
Rate command & 5 & 505 \\
Attitude command & $\frac{7}{16}$ & $\underline{1,151}$ \\
& 2,122 \\
\hline
\end{tabular}

On 16 flights, low dynamic pressure necessitated operation of the reaction control system to stabilize the aircraft. These flights resulted in a, la? seaonds at a dynamic pressure less than $25 \mathrm{psf}$. Twelve of the flights were made with the rate command and attitude hold systems.

In general, flight results have shown that control in the low-dynamicpressure regions can be accomplished with the systems investigated. Piloting techniques and control precision varied, however, with the different systems.

\section{Acceleration Command System}

The piloting technique employed with the acceleration command system and an indication of the maneuverability associated with the system are shown in figure 5, a time history of a $20^{\circ}$ bank-angle maneuver performed above an attitude of 200,000 feet and at a dynamic pressure less than a psf. Stick deflection, control rocket thrust, and the resulting bank angle during the roll maneuver are presented. The control task was to establish a $-20^{\circ}$ bank angle with the reaction controls and to maintain this attitude for approximately 30 seconds. The proportional-thmust characteristics of the acceleration command system were used to some extent during the maneuver, as illustrated by the difference in the relative amplitudes of the rocket thrusts. However, the 
short pulse-type control inputs characteristic of on-off acceleration command systems are also apparent. Experience has shown, in fact, that pilots tend to use the system in an on-off manner rather than as a proportional-thrust system; thus, it appears that similar control characteristics can be attained with a much simpler "on-off" thrust control system.

Experience has also shown that control with the acceleration command system was considerably degraded by the aerodynamic effects resulting from the rapid dynamic-pressure buildup during reentry. This control deterioration is illustrated in figure 6, a time history of the reentry portion of an X-15 highaltitude flight during which the pilot used the open-loop acceleration command system for stabilization. The scheduled $18^{\circ}$ reentry angle of attack for this flight was established at approximately $t=22$ seconds, after which it was held to within $4^{\circ}$ of the desired value. A severe sideslip oscillation with a maximum amplitude of $\pm 5^{\circ}$ at a frequency of approximately $0.3 \mathrm{cps}$ was experienced about the yaw axis. A roll-angle oscillation with a maximum peak-to-peak amplitude of approximately $10^{\circ}$ and frequency equivalent to the yaw-axis oscillation was also experienced.

The pilot was kept extremely busy during this maneuver trying to maintain the correct reentry angle of attack while simultaneously attempting to manually damp the oscillatory motions about the roll and yaw axes which resulted from the increasing dynamic pressure. It was also necessary for him to determine the point at which the reaction controls ceased to be effective and to revert to the nomal aerodynamic controls. The complexity of the reentry control task is apparent when it is realized that these functions must all be performed simultaneously within a few seconds. The pilot rated the task, using the Cooper scale (ref. 4), at 2 (satisfactory) in pitch, 3 (satisfactory) in roll, and 4 (unsatisfactory) in yaw. 
Reaction Augmertation System

Incoppration of the reation augmentation system into the basic arceloration command system considerably reduced the effects of aerodynamic coupling during the reentry maneuver. This improvement is illustrated in figure 7 , which presents angle of attack, angle of sideslip, roll attitude, and the corresponding rocket pulses recorded during an $\mathrm{X}-.2$, reentry with the reaction augmentation system. The large-amplitude rocket pulses represent manual inputs, whereas the shorter pulses are from the roartion augmentation system. The desired reentry angle of attack was held to within approximatoly $2^{\circ}$, and the roll and yaw oscillations experienced during reentry with the acceleration command system (fig. 6) were considerably reduced. The improvement in the ability of the pilot to accomplish the reentry control task is reflected in his rating of 1 (excellent) for pitch, I for roll, and I for yaw.

The ability to control attitude angles simultaneously about all three control axes was also invostigated with the reaction aumentation system. For regions where aerodynamic effectivoness is negligivle, experience has shown that rate dead-band settings of $0.4 \mathrm{deg} / \mathrm{sec}, 0.5 \mathrm{deg} / \mathrm{sec}$, and $I \mathrm{deg} / \mathrm{sec}$ in yaw, pitch, and roll, respoctively, make it possible to control attitude angles with errors of less than $5^{\circ}$.

\section{Rate Command System}

Pilot performance with the rate command system has been, in general, similar to that ith the reaction augmentation system. The transition between aerodynamis and reaction controls is, however, described as somewhat smoother with the rate command system than with the reaction augmentation system, partiy because of the use of one set of controls for both aerodynamic and reaction control.

Proportional control inputs were used extensively with the on-off rate 
command system. This use is illustrated in figure 8, a time history of roll attitude, roll rate, and stick deflection during a right and left roll maneuver performed with the rate command system. The dead-band settings in roll were $1.7 \mathrm{deg} / \mathrm{sec}$. The maneuver was performed at an altitude of 178,000 feet and a dynamic pressure of $16 \mathrm{psf}$. The pilot rolled the vehicle sharply to a $19^{\circ}$ bank angle, then rolled left at an average rate of $5 \mathrm{deg} / \mathrm{sec}$ until a bank angle of $-17^{\circ}$ was obtained. A $5 \mathrm{deg} / \mathrm{sec}$ roll rate was then used to return the aircraft to zero bank angle.

\section{Attitude Hold System}

Control precision is greatly increased with the addition of attitude feedback to the rate command system. This improvement is illustrated in figure 9 , a time history of stick deflection, rocket thrust, and pitch attitude during a constant-pitch-angle control task with the attitude hold system. The dead-band setting in pitch for the task was $2^{\circ}$. The error in maintaining the desired attitude was less than $\pm 1.5^{\circ}$. Only small deviations from the zero-pitch-angle stick position were made by the pilot.

Although the attitude feedback system was originally designed as a holdmode feature, experience has shown that the system can be operated as an attitude command system about the roll axis. The closed-loop response of the system to a step input command about the roll axis is illustrated in figure 10. Dead-band settings in roll were $2.6^{\circ}$ for attitude and $1.7 \mathrm{deg} / \mathrm{sec}$ for rate. The maneuver was performed at an altitude of 209,000 feet and a dynamic pressure of 4 psf. The pilot rolled the vehicle with the reaction controls to a $30^{\circ}$ bank angle and released the control stick to allow the system to return' the aircraft to zero bank angle. Approximately 6 seconds (with a $4^{\circ}$ overshoot) were required to return to zero bank angle.

The angle-of-attack hold mode was incorporated into the attitude system to provide a means of more accurately controlling this parameter, particularly 
during reentry. Tho angle-of-attack feedback signal is developed by a flowdirection sensor in the nose of the aircraft. During the initial stage of. reentry, when dynamic pressure has started to increase, the pilot switches from pitch-attitude hola to angle-of-attack hola. This transfer takes approximately 3 seconds during which the pitch channel functions in the rate command mode. Because of the large increase in dynamic pressure during this time and the differences between the commanded and trim angle of attack, a nose-down pitching moment generally occurs which must be compensated for by the pilot. When the transfer is complete and with dead-band settings of $1.7^{\circ}$, the vehicle angleof-attack excursions are held to within $3^{\circ}$. The angle-of-attack control accuracy experienced in this mode has not been significantly greater than that experienced with the rate command or rate damping systems during the reentry maneuver.

\section{Propellant Usage}

A significant criterion for evaluating the efficiency of the reaction control systems investigated is the propellant required by each system to maintain adequate vehicle stavility and control. The fuel-consumption characteristics associated with the $\mathrm{X}-15$ reaction control systems are summarized in figure 11, which shows the propellant consumed by cach system during several high-altitude flights as a function of the time spent at a dynamic pressure less than 25 psf. The control task during these flights was primarily to stabilize about all three axes, with most of the inputs being compensatory.

Propellant consumption was highest with the proportional acceleration command system. The lack of damping moments is consiaered to be a majon factor in reduced control efficiency. Difficulty in judging precisely the necessary magnitude of control input about all three axes resulted in many more control inputs and higher fuel consumption than were necessary to perform the given 
task. The damping moments provided by the reaction augmentation system increased the overall control efficiency, as indicated by the reduced fuel consumption. Fuel usage with the attitude feedback signal was slightly higher than with rate feedback only. This increase is characteristic of the tighter control demanded by the attitude system that results in more control inputs.

Propellant consumption with the rate command system was considerably less than with the acceleration command and the reaction augmentation systems. The reduction in the total impulse required to maintain vehicle control indicates the increased efficiency possible with a rate command type of control.

\section{CONCLUDING REMARKS}

The X-15 program has offered the opportunity to assess the problems of controls and operational methods required for stabilizing manned aircraft in low-dynamic-pressure regions and in reentries from high altitudes.

Most of the problems encountered during development of the $\mathrm{X}-15$ reaction control systems resulted from the limited selection of hardware materials that could be used in fabricating components which would function reliably when exposed to the hydrogen-peroxide propellant. After an unsuccessful experience with aluminum components, a reliable system was developed with all stainlesssteel components. It is believed that the practical experience gained can be applied to reaction-control-system design in general. Careful consideration of propellant and hardware compatibility, environmental conditions, and airframe structural modes is necessary in the design of any reaction control system used for control of any vehicle at low dynamic pressures.

Flight experience with the $\mathrm{X}-15$ reaction control systems has shown that open- or closed-loop control, in regions where aerodynamic effectiveness is negligible, can be readily accomplished. Closed-Ioop control, however, greatly improved the pilot's ability to control the vehicle during reentry where 
aenodynami coupling becomes appreciabl. Higher control efficiencies were also experienced with the elosed-loop systems with regara to both precision of control task and propeliant consumption. For stabilizing tasks in which precise angle control is not required, the rate command system was superior to the other systems investigated. Inclusion of attitude feedback resulted in improved control but increased the propellant requirements.

\section{SYMBOLS}

$\begin{array}{ll}F & \text { attitude rocket thrust } \\ h & \text { altitude, ft } \\ p & \text { roll rate, deg/sec } \\ q & \text { aynamic pressure, psf } \\ t & \text { time, sec } \\ t_{q} 5 & \text { time below a dynamic pressure of es psf, sec } \\ W_{C} & \text { propellant consumption, lb } \\ \alpha & \text { angle of attack, deg } \\ \beta & \text { angle of sideslip, deg } \\ \delta_{\mathrm{S}} & \text { stick deflection, percent of maximum } \\ \theta & \text { pitch-attitude angle, deg } \\ \phi & \text { roll-attitude angle, deg }\end{array}$




\section{REFERENCES}

1. Holleman, Euclid C., and Stillwell, Wendell H.: Simulator Investigation of Command Reaction Controls. NACA RM H58D22, 1958.

a. Love, James E., and Stillwell, Wendell H.: The Hydrogen-Peroxide Rocket Reaction-Control System for the X-1B Research Airplane. NASA IN D-185, 1959.

3. Reisert, Donald, and Adkins, Elmor J.: Flight and Operational Experiences With Pilot Operated Reaction Controls. ARS Jour., vol. 32, no. 4, Apr. 1962, pp. 626-631.

4. Cooper, George E.: Unāerstanding and Interpreting Pilot Opinion. Aero. Eng. Rev., vol. 16, no. 3, Mar. 1957, pp. 47-51, 56. 


\section{$X-15$ AIRPLANE}

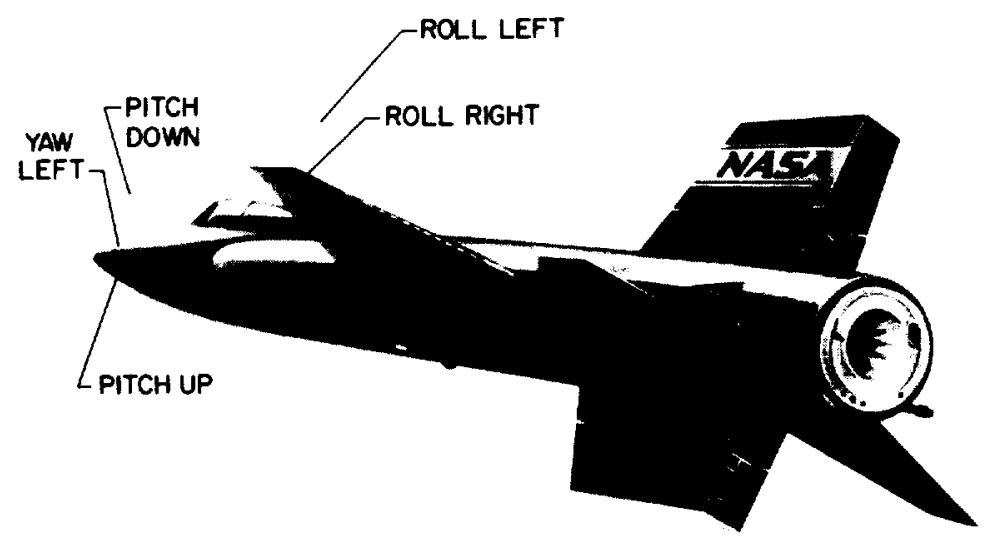

Figure I

\section{X-I5 REACTION-CONTROL-SYSTEM COMPONENTS}

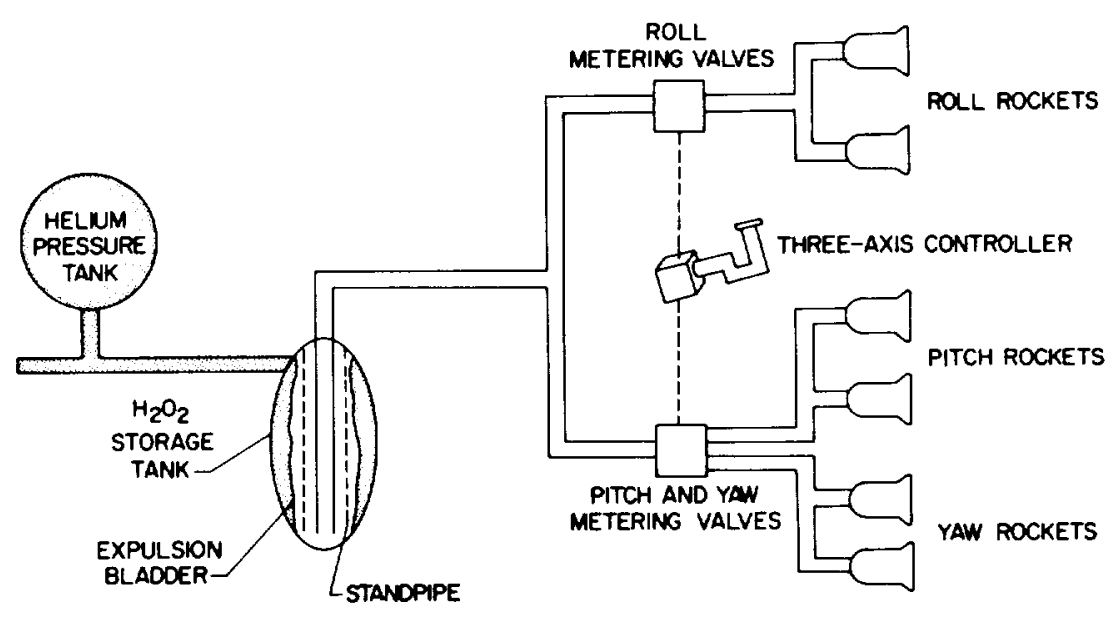

Figure? 


\section{X-I5 REACTION-CONTROL-SYSTEM CONFIGURATION}

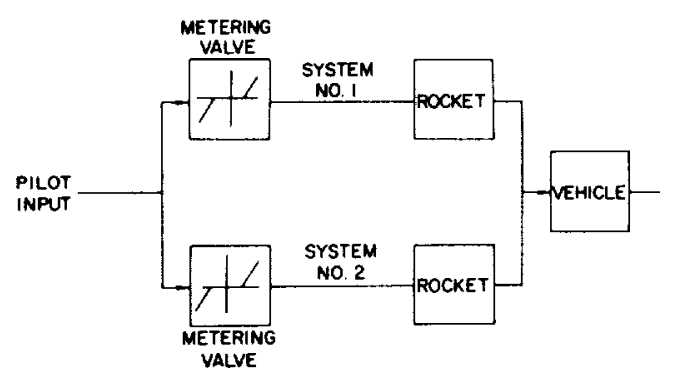

(a) Accelerotion command

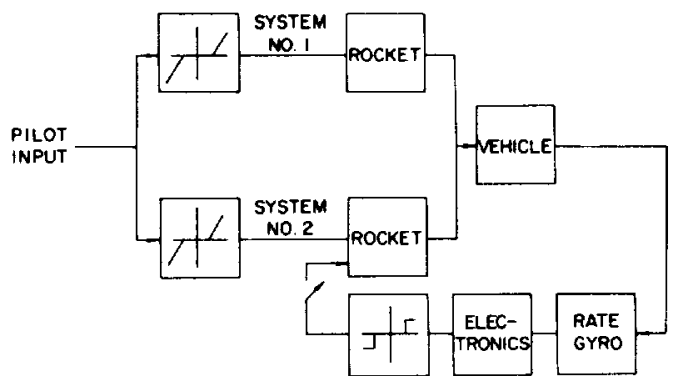

(b) Reaction ougmentation

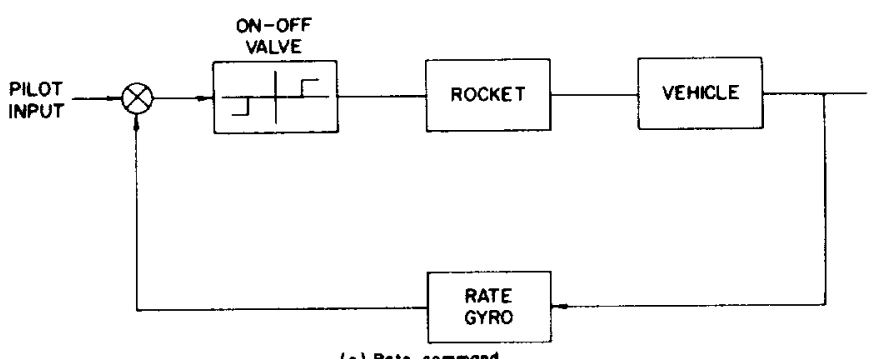

(c) Rote command

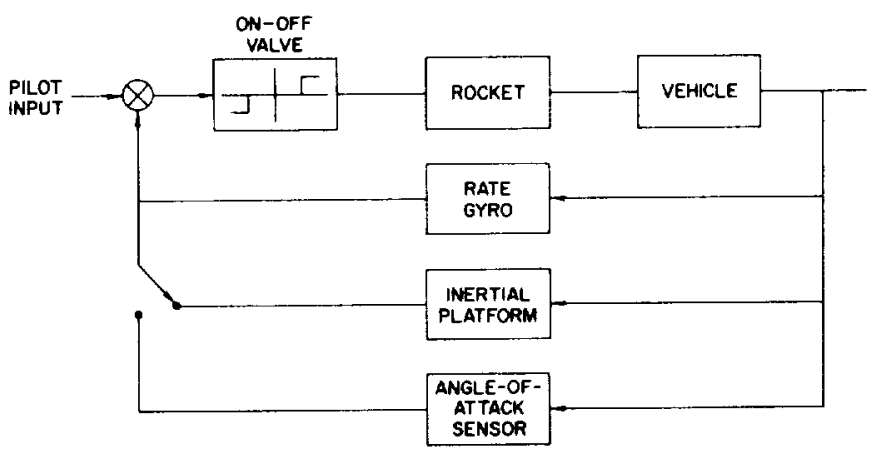

(d) Altitude nold

Figure 3 
TYPICAL X-15 HIGH-ALTITUDE FLIGHT

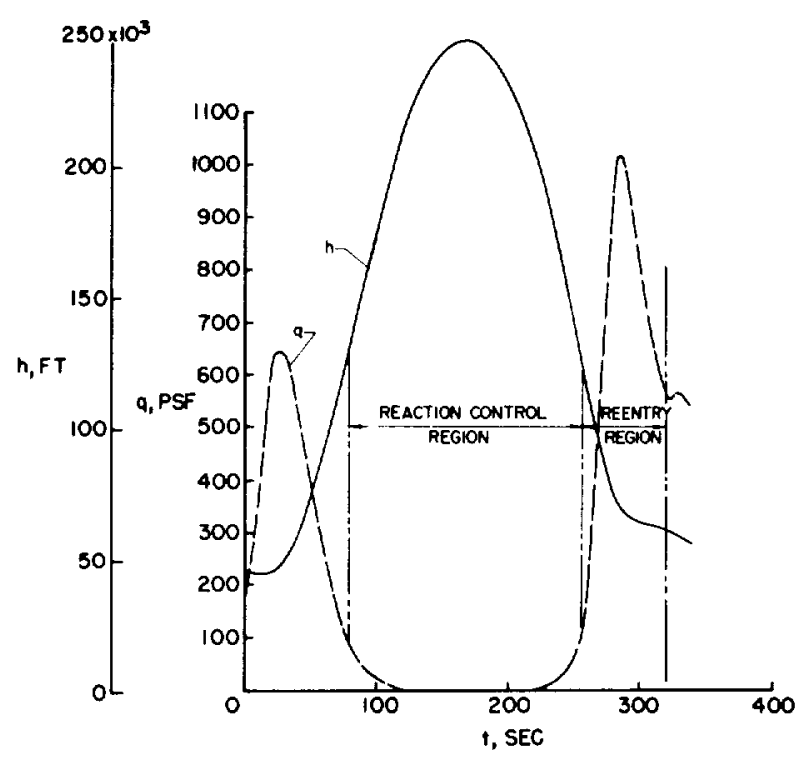

Figure 4

ROLL MANEUVER USING ACCELERATION COMMAND SYSTEM
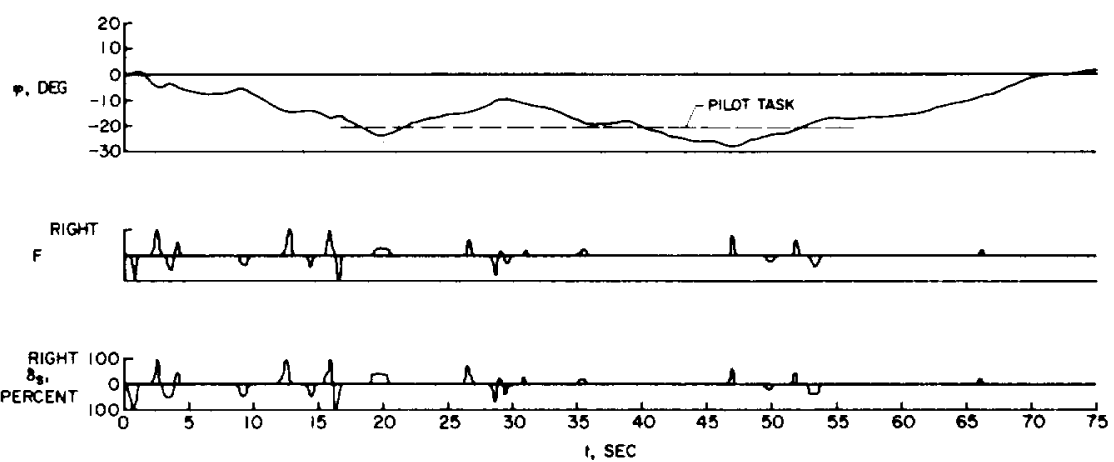

Figure 5 
REENTRY USING ACCELERATION COMMAND SYSTEM

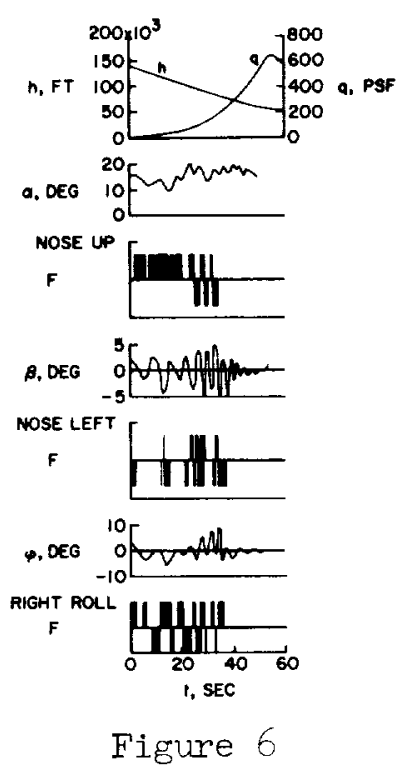

REENTRY USING REACTION AUGMENTATION SYSTEM

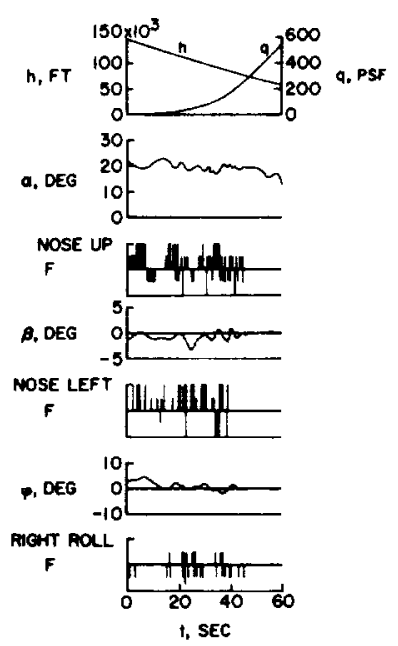

Figure 7 


\section{RATE COMMAND SYSTEM ROLL MANEUVER}

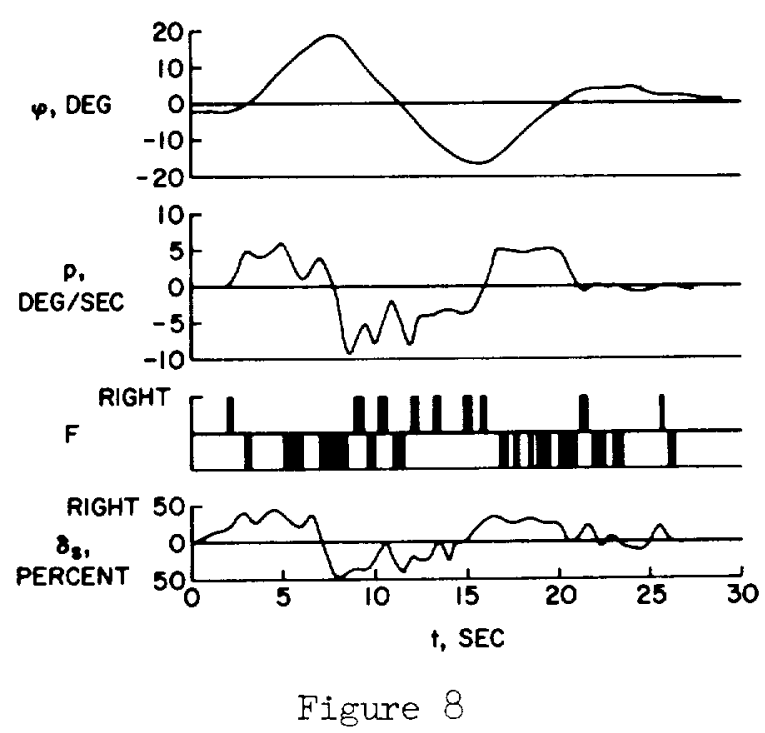

\section{ATTITUDE HOLD SYSTEM PITCH CONTROL TASK}
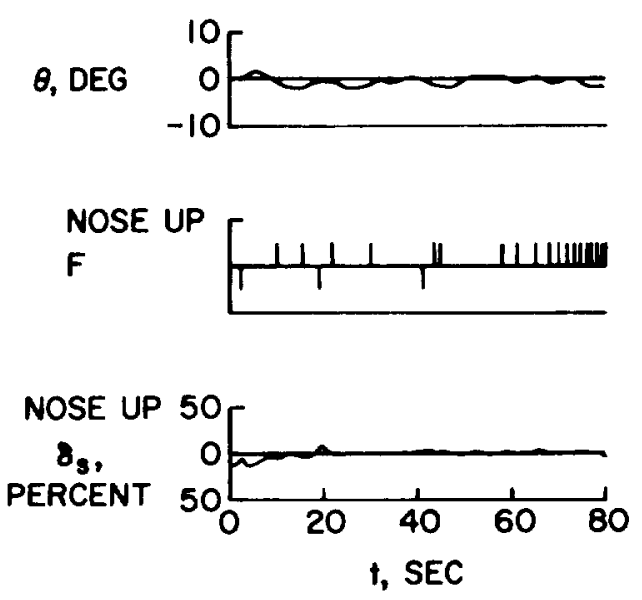

Figure 9 
STEP RESPONSE OF ATTITUDE COMMAND SYSTEM

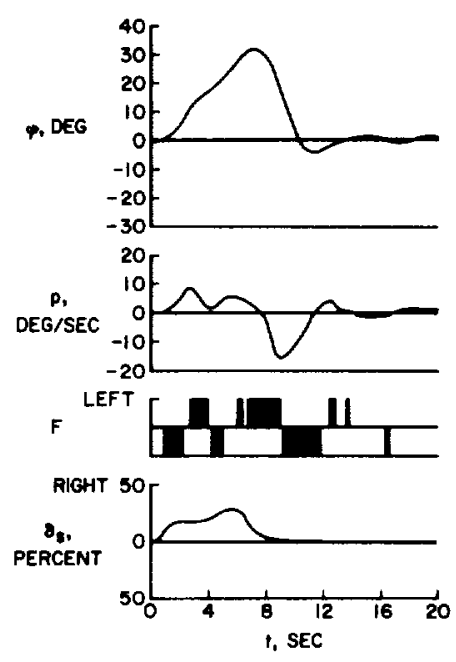

Figure 10

\section{X-15 REACTION-CONTROL-}

SYSTEM FUEL USAGE

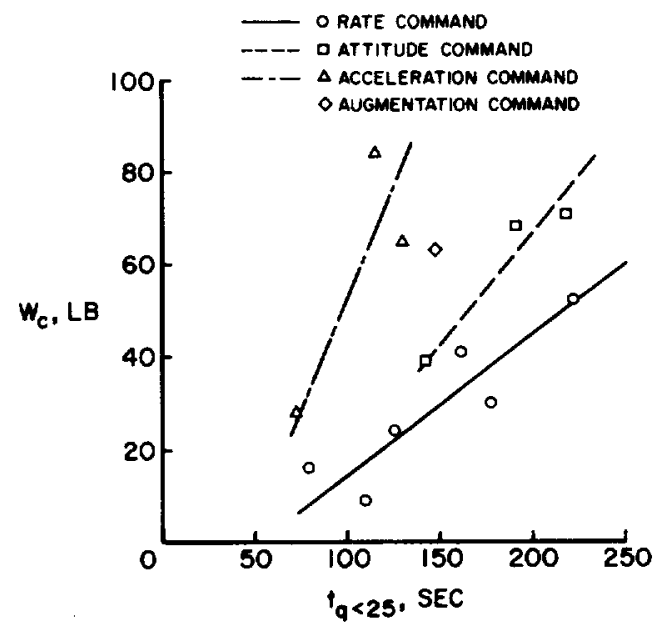

Figure 11 